\title{
A pós-graduação stricto sensu em Educação Física no Brasil e suas dinâmicas figuracionais
}

\author{
The stricto sensu postgraduate program in Physical Education in Brazil and its figurational \\ dynamics
}

\author{
El programa de posgrado stricto sensu en Educación Física en Brasil y su dinámica \\ figuracional
}

Fabiane Castilho Teixeira Breschiliare ${ }^{a}$ (D) Caroline Broch $^{\mathrm{b}}$ (D), Juliana Pizania (D), Vinicius Machado de Oliveira ${ }^{*}$ (i), Juliano de Souzac ${ }^{(1)}$, leda Parra Barbosa Rinaldic

Palavras-chave: Atividade científica; Educação física; Pós-graduação Stricto Sensu;

Sociologia configuracional.

\section{Keywords:}

Scientific activity; Physical education; Stricto sensu postgraduate; Configurational sociology.

Palabras clave: Actividad científica; Educación física; Postgrado stricto sensu; Sociología configuracional.

\section{RESUMO}

O objetivo da pesquisa foi analisar a configuração da pós-graduação stricto sensu em Educação Física no Brasil a partir da compreensão de coordenadores e egressos de dois programas da área. Realizou-se uma entrevista semiestruturada com os sujeitos pesquisados. As informações foram discutidas à luz da teoria eliasiana. Evidenciou-se que a organização interna, a produção intelectual, o status acadêmico e a formação são elementos que influenciam essa configuração e que se firma uma polarização entre pesquisa e docência na formação em voga. É possível concluir que, os avanços que decorrem dessa dinâmica favorecem o fortalecimento da atividade científica da área e que a polarização identificada não favorece uma formação mais ampliada para os estudantes.

\begin{abstract}
The aim of this research was to analyze the configuration of the stricto sensu post-graduation in Physical Education in Brazil from the understanding of coordinators and graduates of two programs in the area. A semi-structured interview was conducted with the researched subjects. The data were discussed in light of Eliasian theory. It was evident that the internal organization, intellectual production, academic status, and training are elements that influence this configuration and that polarization between research and teaching is established in the educational training. It was concluded that the advances that result from this dynamic favor the strengthening of scientific activity in the area and that the identified polarization does not favor a better education for students.
\end{abstract}

\section{RESUMEN}

El objetivo de la investigación fue analizar la configuración del posgrado stricto sensu en Educación Física en Brasil a partir de la comprensión de los coordinadores y egresados de dos programas en el área. La información se discutió a la luz de la teoría sociológica de Norbert Elias. Se evidenció que la organización interna, la producción intelectual, el estatus académico y la formación son elementos que inciden en esta configuración y que se establece una polarización entre investigación y docencia en la formación en boga. En conclusión, se destaca que los avances que se derivan de esta dinámica favorecen el fortalecimiento de la actividad científica en el área y que la polarización identificada no favorece una formación más amplia para los estudiantes.

\footnotetext{
aUniversidade Federal de Santa Catarina, Departamento de Educação Física. Florianópolis, SC, Brasil.

${ }^{\text {b}}$ Centro Universitário de Maringá, Departamento de Educação Física. Maringá, PR. Brasil.

'Universidade Estadual de Maringá, Programa de Pós-graduação Associado em Educação Física. Maringá, PR, Brasil.
}

\author{
*Autor correspondente: \\ Vinicius Machado de Oliveira \\ E-mail: oliveira_vm@hotmail.com




\section{INTRODUÇÃO}

A história da pós-graduação stricto sensu em Educação Física no Brasil é recente. O primeiro programa de mestrado acadêmico foi instituído em 1977, na Universidade de São Paulo (USP), com as finalidades de capacitar docentes para o ensino superior e promover o desenvolvimento de conhecimentos na área por meio da pesquisa (Amadio, 2007). No final dos anos 2000, o Brasil contava com dez programas de pós-graduação em Educação Física recomendados pela Coordenação de Aperfeiçoamento de Pessoal de Nível Superior (CAPES), do Ministério da Educação (MEC) (Kokobun, 2003).

Nesse ínterim, as políticas de pós-graduação no Brasil direcionaram-se inicialmente à qualificação dos docentes para a atuação no ensino superior (Tani, 2016). Tal qualificação foi orientada por um perfil docente preocupado, em linhas gerais, em ofertar um ensino qualificado para a graduação. Não obstante, com o passar dos anos, a atividade científica foi incorporada como ação estratégica para o desenvolvimento deste setor, assumindo, inclusive, a centralidade das suas intenções e ações (Lazzarotti et al., 2012; Furtado e Hostins, 2014; Turnes, 2014; Lazzarotti et al., 2014).

Convém destacar que, no bojo da sua criação, na década de 1950, a CAPES se concentrou na qualificação dos docentes universitários, por considerar que essa era a principal demanda a ser suprida (Turnes, 2014; Vogel, 2015). A expansão desse nível de ensino na década de 1970 fortaleceu a preocupação da CAPES em estabelecer um padrão de qualidade para os cursos, que foi projetado no I Plano Nacional de Pós-Graduação (PNPG).

No entanto, com a nova configuração da pósgraduação brasileira na década de 1980 , esse nível de ensino foi desafiado a qualificar o corpo docente para a produção de conhecimento (Tani, 2016). De tal modo, a partir da década de 1980, a avaliação da pós-graduação assumiu uma posição de destaque (Nunes, 2014).

O mapeamento na literatura identificou que as produções científicas que tratam da organização da pós-graduação apresentam críticas em relação ao modo com que a política científica incide na formação dos pósgraduandos. Em linhas gerais, as críticas sinalizam que, a partir da supervalorização da produção científica e da cobrança exacerbada de publicações a orientadores, a formação do docente é colocada em segundo plano, o que fragiliza o processo formativo oferecido na pósgraduação (Moreira e Tojal, 2013; Silva et al., 2014; Lazzarotti et al., 2014; Schnetzler et al., 2015).

Embora estudos sobre essa dinâmica tenham se acumulado na literatura, há lacunas nas produções acadêmicas, no sentido de contemplar análises que consideram o papel desempenhado pelos atores sociais que interagem com esse sistema. Assim, consideramos a relevância de entender essa dinâmica buscando compreender as ações dos sujeitos e a influência que essas ações exercem na configuração em análise. Isto é, entendemos que o sistema vigente influencia a organização dos programas de pós-graduação, mas também sofre influências da sua dinâmica e das intenções e decisões dos sujeitos. Frente ao diagnóstico destas lacunas, o presente estudo buscou dar voz aos sujeitos inseridos nessa configuração e teve por objetivo analisar a configuração da pós-graduação stricto sensu em Educação Física no Brasil a partir da compreensão de coordenadores e egressos de dois programas da área.

Dentre as preocupações do estudo, em particular, procuramos verificar variáveis relacionadas à dinâmica interna dos cursos; a produção acadêmico-científica entre os indivíduos da configuração; o status acadêmico enquanto capital dentro da estrutura; e o processo de formação acadêmica no contexto da Educação Física brasileira.

\section{DECISÕES TEÓRICO-METODOLÓGICAS}

A pesquisa possui características qualitativas e descritivas (Gil, 2010; Minayo et al., 2011). Fizeram parte do estudo coordenadores e egressos de programas de pós-graduação em nível de mestrado e doutorado acadêmico em Educação Física do estado do Paraná, recomendados e reconhecidos pela CAPES em 2018.

Para a escolha intencional dos participantes, foram adotados os seguintes critérios: a) buscou-se equilíbrio entre representantes das diferentes linhas de pesquisa; b) considerou-se coordenadores e egressos de ambos os programas. Após esse filtro inicial, o escopo empírico da pesquisa foi definido em três coordenadores (dois em pleno exercício da função e um de gestão anterior) e cinco egressos de doutorado dos programas investigados. Esse quadro amostral de oito participantes foi definido com base no grau de profundidade da pesquisa, a qual não poderia ser realizada com um número elevado de participantes, tendo em vista a densidade das coletas e das análises, fundamentalmente de cariz qualitativa e teórica.

O convite à participação na pesquisa deu-se por meio do envio de mensagem para o endereço eletrônico de cada um dos sujeitos. Explicou-se o enfoque da pesquisa, o objetivo e seus detalhamentos metodológicos. Na sequência, cada um dos participantes assinou o termo de consentimento livre e esclarecido (TCLE). A pesquisa foi aprovada pelo Comitê Permanente de Ética em Pesquisa com Seres Humanos - COPEP da Universidade Estadual de Maringá - PR, a partir do Parecer Consubstanciado no 2.410.413.

Para a composição dos dados, recorreu-se ao emprego de entrevistas semiestruturadas. Estruturou-se dois roteiros de entrevistas. $O$ roteiro direcionado aos coordenadores continha 12 questões, com foco nas seguintes dimensões: perfil do entrevistado; estrutura organizacional e pedagógica do Programa; as exigências da política de pós-graduação stricto sensu; a produção científica; a estrutura curricular; a proposta formativa do Programa. O roteiro estruturado para os egressos continha 
14 questões, com foco nas seguintes dimensões: perfil do entrevistado; estrutura pedagógica do Programa; a produção científica; o estágio de docência; características das disciplinas cursadas; a proposta formativa do Programa. Para a elaboração desses instrumentos, foram organizadas duas matrizes analíticas, validadas por três professores doutores da área. Quanto às entrevistas, todos os informantes foram representados por siglas, sendo $(C 1, C 2, C 3)$ para os coordenadores e (E1, E2, E3, E4, E5) para os egressos.

Para a categorização dos dados, recorreu-se aos indicativos do método de análise de conteúdo de Bardin (2011), eleito por remeter a procedimentos sistemáticos e objetivos da descrição de conteúdos de mensagens, além de possibilitar uma leitura e análise profunda dos seus conteúdos. As categorias de análise foram elaboradas à posteriori, por procedimento indutivo, apropriando-se da literatura pesquisada e da matriz analítica da pesquisa (Castro et al., 2011). Além dos contributos do método de Bardin, mobilizou-se, paralelamente, o referencial teórico do sociólogo alemão Norbert Elias para análise das informações.

\section{RESULTADOS E DISCUSSÃO}

Em linhas gerais, a análise destacou elementos que impactam a dinâmica dos cursos investigados, com destaque para informações de como o jogo acadêmico se configura no contexto da pós-graduação stricto sensu em Educação Física.

Na sequência são apresentados os pontos basilares dos relatos dos pesquisados, socializados em quatro interfaces de discussão, a saber: [1] a dinâmica interna dos cursos de pós-graduação em Educação Física; [2] a produção intelectual na pós-graduação em Educação Física; [3] o status acadêmico na pós-graduação em Educação Física; [4] a formação na pós-graduação em Educação Física.

\section{A DINÂMICA INTERNA DOS CURSOS DE PÓS-GRADUAÇÃO EM EDUCAÇÃO FÍSICA}

A pós-graduação brasileira tem passado por inúmeras transformações, sobretudo nas últimas décadas, momento em que se acentuou o seu desenvolvimento (Tani, 2016). Dentre essas transformações, por exemplo, notabilizam-se normativas de instâncias superiores que alteraram a dinâmica de produção científica e formação acadêmica nas universidades. Nesse cenário, os programas têm buscado responder positivamente às normativas que balizam o nível stricto sensu, com destaque para as orientações do PNPG (2011-2020), e para os critérios de avaliação da CAPES.

Notam-se calorosas discussões na academia sobre os critérios de avaliação dos programas e o reflexo disso na organização dos cursos e na rotina de trabalho dos agentes que atuam na pós-graduação. No formato atual, a criação e a conservação dos cursos estão condicionadas ao cumprimento das exigências do sistema avaliativo, especialmente no que se refere à produção científica qualificada (Mendes e lora, 2014).

Aliás, as exigências da CAPES quanto à produção intelectual foi um dos aspectos destacados pelos coordenadores pesquisados, como pode-se inferir no relato de C2: "[...] a exigência suprema é a produção intelectual". Não obstante, em que pesem as interferências postuladas pela PNPG e CAPES na rotina dos programas, os coordenadores $(\mathrm{C} 1, \mathrm{C} 2, \mathrm{C} 3)$ ressalvaram que os cursos têm uma relativa autonomia na tomada de decisões.

Essa percepção evidenciou-se em algumas falas dos informantes, a exemplo da seguinte afirmação de C3: "Quem traça os caminhos e quem escolhe as perspectivas a partir daquilo que está posto são os programas de pós-graduação". Em linhas gerais, isso quer dizer que, o direcionamento que é dado às exigências apresentadas pela CAPES passa pelos critérios estabelecidos no âmbito dos próprios programas.

Essa é uma via de mão dupla, pois, o sistema de avaliação influencia a organização da pós-graduação, mas também sofre influências da sua dinâmica, revelando uma lógica de relações de interdependência que independem da posição ocupada pelos indivíduos (Elias, 2011), bem como uma espécie de "cumplicidade objetiva" entre as instituições (Lahire, 2017), uma vez que as ações dos indivíduos reverberam nos diferentes polos que orbitam o campo acadêmico-científico.

É possível entender que os fatos sociais precisam ser dimensionados como não exteriores aos sujeitos, isto é: "A sociedade, como sabemos, somos todos nós; é uma porção de pessoas juntas" (Elias, 1994, p. 13). De modo geral, a sociedade só existe porque há um expressivo quantitativo de indivíduos, e as estruturas sociais só funcionam porque os sujeitos deliberam ações em um contexto de interdependência (Elias, 1994). Assim, parece existir essa relação de "cumplicidade objetiva" entre as instituições regulamentadoras da atividade científica com os programas de pós-graduação, em que pese, é claro, a balança de poder não esteja devidamente equilibrada devido ao maior peso funcional que a CAPES, por exemplo, exerce dentro do interior da configuração. Assim, a instituição CAPES apresenta uma maior influência nas imposições das regras do jogo, ainda que os agentes também exerçam sua influência no sistema procurando equilibrar forças.

Não obstante, embora existam esforços para equalizar os interesses de ambos os lados, essa relação nem sempre é permeada por consensos. Um exemplo dessas dissonâncias se manifesta em relação às próprias regras quanto aos prazos para a conclusão dos cursos, em especial em nível de mestrado cujo tempo estipulado, ao menos aos olhos dos coordenadores e egressos, é um fator que impacta a rotina de trabalho e que reflete no aligeiramento da formação, tal qual como discriminado também por Mendes e lora (2014). 
Vale pontuar que, uma parcela de estudantes só consegue defender seus trabalhos após o pedido de prorrogação e, em alguns casos, há a desistência do curso. Dados nesse sentido já tem circulado na literatura, como por exemplo, o estudo realizado por Fernandes et al. (2017), que identificou que entre os anos de 2000-2016, $38,48 \%$ dos alunos ingressantes em programas de pósgraduação brasileiros não concluíram seus cursos.

É preciso considerar que o não cumprimento dos prazos para a defesa dos trabalhos é desfavorável para os programas, já que esse aspecto é um dos fatores avaliados pela CAPES. Diante disso, faz-se o seguinte questionamento: quais têm sido as prioridades dos sujeitos com relação à formação? Uma leitura por via da teoria eliasiana dá indicativos de que no jogo da pósgraduação, a coerção que essa configuração específica exerce, faz com que os indivíduos tenham que realizar escolhas sobre aquilo que consideram mais pertinentes para se manter no jogo, mesmo que, de alguma maneira, essas escolhas superem outras também importantes.

Um exemplo disso é o fato de se destacar na hierarquia de prioridades dos sujeitos, a mobilização de estratégias para incrementar a produção intelectual. Ao discutir as prioridades do grupo de pesquisa ao qual se vinculou no doutorado, o E1 ressaltou: "[...] existia uma estratégia que os próprios integrantes do grupo acabavam colocando em termos de publicação".

Vale sinalizar que as estratégias dos sujeitos seguem os rumos traçados para o incremento da pósgraduação brasileira, mas não necessariamente seguem as predileções dos indivíduos. Na esteira desses vínculos humanos, as ações para alcançar a ascensão são definidas por aqueles que apresentam um potencial maior de poder e que podem controlar mais o andamento do jogo. Pois, ainda que existam as relações de interdependência entre os indivíduos em um mesmo espaço, a balança de poder pode pender mais para aqueles que melhor operam sobre as regras do jogo, ou entre aqueles que ocupam uma posição influente na configuração (Elias, 2011).

Por conseguinte, se a publicação é a principal moeda do sustento da pós-graduação, logo atender essa premissa é fundamental, não só para se manter no jogo, mas também para galgar melhores espaços e dispor de maiores prerrogativas. Em face disso, apresentamos o posicionamento dos agentes sobre a produção intelectual na pós-graduação.

\section{A PRODUÇÃO INTELECTUAL NA PÓS-GRAD- UAÇÃO EM EDUCAÇÃO FÍSICA}

Prosseguindo a análise realizada, destacam-se os relatos dos sujeitos sobre a produção científica na pósgraduação. Alguns egressos se posicionaram e ratificaram a importância da produção científica: "Era bem puxado nesse ponto de produção se você quisesse manter sua bolsa" (E2). "A produtividade era constantemente cobrada, e o principal impacto era na disputa por bolsas, principalmente pelo fato dos discentes da área de Desempenho Humano e Atividade Física possuírem um maior volume de produção [...] (E4). Na contramão desses relatos, um dos egressos se manifestou favorável à dinâmica de produção vigente: "Eu acho que se eu pudesse escolher, o meu critério seria quase que exclusivamente a produção" (E5).

Além da necessidade de publicação para os processos de bolsas das universidades, os egressos informaram que a cobrança quanto à produção intelectual alcançou o espaço formativo das disciplinas cursadas. O E2 comentou: "Eu diria que isso acontece praticamente em todas as disciplinas. Você precisa produzir um artigo como produto da disciplina e, de preferência, que ele seja submetido a algum periódico". $\mathrm{Na}$ mesma linha argumentativa, E1 declarou que no contexto das disciplinas "[...] existia um compromisso claro da necessidade de publicar", o que de certa forma foi endossado também na fala de E2: "Muitas vezes são artigos que são feitos e você não tem tempo de amadurecer os textos e são feitos para publicar, publicar e publicar".

Esse conjunto de estratégias relatado pelos egressos tem sido alvo de debates na academia, que versam sobre: a) os impactos das cobranças de produtividade na formação dos estudantes; b) os reflexos da pressão por publicação no processo avaliativo das disciplinas da pós-graduação; c) a relação existente entre a imaturidade dos estudantes com a pesquisa e a fragilidade das publicações, sobretudo no mestrado; d) a atribuição dos méritos e benefícios acadêmicos quase exclusivos pela produção científica (Alcadipani, 2011; Mendes e lora, 2014; Silva et al., 2014).

Em paralelo ao que essa literatura aponta, a percepção dos coordenadores sobre as exigências com a produção intelectual perpassa pela necessidade desses agentes traçarem estratégias para se manterem no jogo da pós-graduação. Sobre essa dinâmica, C1 ressalta: "Quando você está dentro do sistema, você vê certa lógica, muitas vezes não é o que você gostaria que fosse, mas é jogar o jogo mesmo". Nessa direção, C2 manifestou: "De acordo com o nível de competição existente hoje, de exigências em termos de produção intelectual, os docentes para sobreviverem dentro disso, precisam ter estratégias, que sejam efetivas, eficientes e eficazes".

Essas narrativas dão indicativos de que a relativa autonomia da pós-graduação em Educação Física impõe certa coerção sobre a tomada de posição de seus jogadores. Com base em Elias (2011), destaca-se que as ações dos sujeitos não são desencontradas, tampouco individuais, mas são ajustadas em conformidade com as disposições firmadas no referente nível de ensino.

Dessa forma, os coordenadores têm a percepção que os critérios aplicados à produção intelectual são definidos dentro da própria área. Destaca-se a narrativa de C2: "A produção intelectual é uma medida arbitrária, mas 
mesmo assim cada área tem condições de escolher o seu sarrafo". Em linhas gerais, deste exemplo, depreende-se que os agentes não só atingem os níveis necessários para preservar-se ativos no jogo, como também ditam o ritmo que devem seguir no interior da área, como relatado por C3: "Mas, de certo modo, há uma certa flexibilidade, uma certa autonomia na organização da forma como isso vai ser gestado nos programas".

Ainda nesse debate, C2 complementa a sua fala e reitera que essa organização gera insatisfação nos pares, já que, em muitos casos, não se sentem representados por tais condições. Ademais, ele entende que os programas são prejudicados na medida em que não estão preparados para uma competição mais ampla, e não contemplam uma produção intelectual de maior peso. Assim, equalizar os indivíduos dos diferentes subdomínios da pós-graduação para metas em comum se torna um dos maiores desafios.

Esse diagnóstico fica mais evidente quando os coordenadores reconhecem a existência de tensionamentos entre as subáreas que compõem os programas, quais sejam, biodinâmica, sociocultural e pedagógica. Em relação a essas diferenças, C2 tratou da discrepância entre as diferentes linhas no que tange às dinâmicas de publicação, ao afirmar: "A Educação Física tem dois grandes eixos, o eixo biológico, e o eixo pedagógico e sociocultural, em que a veiculação da produção do conhecimento é muito diferenciada e acaba sendo avaliada pelo mesmo sarrafo". Nessa direção, C3 argumentou que "[...] a subárea biodinâmica tem um espaço considerável nas coordenações dos programas e as subáreas sociocultural e pedagógica cada vez mais têm menos pessoas nesses assentos".

Vale destacar que os acirramentos existentes entre as Ciências Humanas e as Ciências Naturais na Educação Física já estão demarcados na literatura (Souza e Sanchez Gamboa, 2009; Manoel e Carvalho, 2011; Furtado e Naman, 2014; Lazzarotti et al., 2014). Essa polaridade acaba refletindo em discordâncias entre os sujeitos que se vinculam à pós-graduação. Uma situação que vem sendo recorrente são as tensões estabelecidas entre os pesquisadores das diferentes subáreas da Educação Física no embate acerca da especificidade da produção, da veiculação e qualificação do conhecimento (Souza, 2019).

A partir das contribuições de Elias (2011), depreende-se que os conflitos vivenciados no interior das configurações são provas de força entre grupos interdependentes, dimensionados pelo potencial de um grupo reter aquilo que o outro necessita. No caso da pósgraduação, aqueles que apresentam um potencial mais alvissareiro de poder tendem a definir mais as exigências e os critérios a serem contemplados pelos pares. Todavia, cabe ressalvar que, o poder precisa ser considerado como característica estrutural de uma relação, que justamente por ser estrutural, não pode ser avaliado nem como bom, nem como mal (Elias, 2011).
Dando continuidade as análises, na sequência, apresentamos as indicações dos coordenadores e egressos sobre o status acadêmico na pós-graduação.

\section{O STATUS ACADÊMICO NA PÓS-GRADUA- ÇÃO EM EDUCAÇÃO FÍSICA}

De modo geral, na realidade em voga, os relatos dos sujeitos do estudo sinalizam que a pesquisa, a produção intelectual e a posição que os pesquisadores ocupam na dinâmica da pós-graduação são decisivos para restituir o sentido do jogo que vem se reproduzindo não só na área da Educação Física, como no campo científico brasileiro e global de uma forma mais ampla.

Cabe explorar os seguintes relatos: "O que acontece na universidade é que as pessoas só respeitam o pesquisador", (C1). "A produção intelectual é hoje para a pós-graduação, a grande moeda corrente" (C2). "Os programas têm a sua própria vaidade, os programas têm pesquisadores que são movidos também por vaidade, ou por necessidade de ascensão, de visibilidade, e essa disputa acaba sendo acirrada (C3).

Tanto entre os programas, como entre os professores há uma competição, às vezes até velada, por status e prestígio acadêmico (Furtado e Hostins, 2014). No entanto, muitas vezes, esse prestígio não é alcançado de forma solitária, pelo contrário, os pesquisadores têm ciência de que, quanto mais alargadas forem as suas redes acadêmicas, maiores são as chances de ganhar visibilidade no cenário.

O referencial teórico eliasiano ajuda a problematizar tal quadro social. Para o sociólogo, a disputa por prestígio apresenta íntima relação com a busca por poder, pois o grau de prestígio é determinante para o grau de influência que os indivíduos podem exercer uns sobre os outros (Elias, 2001). Na análise deste estudo, é possível inferir que a busca por prestígio e status na pós-graduação brasileira é manifestada entre os pares, tendo em vista a coerção que essa configuração exerce na tomada de decisão dos jogadores, materializada pela necessidade de conquistar e/ou manter suas posições acadêmicocientificas.

Os achados dão pistas de que, nessa configuração, a produção intelectual é revelada como uma moeda de troca instituída no enredo da competição que se firma entre os pesquisadores. Aliás, a manutenção desse status e seus benefícios é um moto contínuo, na medida em que se renova e se exige cada vez mais produção dos seus detentores (Pires e Poffo, 2017).

Não obstante, como se sabe, a pós-graduação não se resume à produção científica, ainda que esse fator seja considerado um dos elementos fulcrais para a sobrevivência dos programas. Há, além disso, o processo formativo dos discentes que além de pesquisadores potenciais, precisam tornar-se docentes aptos a atuarem no ensino superior. Sabendo disso, discute-se 
na sequência, como os agentes percebem o processo formativo dentro dos programas.

\section{A FORMAÇÃO NA PÓS-GRADUAÇÃO EM EDUCAÇÃO FÍSICA}

A mudança de perspectiva da pós-graduação, especialmente a partir da década de 1990 , da qualificação para a docência para a qualificação para a pesquisa (Turnes, 2014), considerada como um marco para o cotidiano da pós-graduação, foi abordada nas entrevistas realizadas.

Alguns entrevistados argumentaram sobre as mudanças ocorridas no processo formativo, sobretudo em relação ao predomínio da pesquisa em detrimento da formação docente. Em síntese, os entrevistados pontuaram que décadas atrás não existia uma preocupação tão rigorosa com a publicação, tessitura que foi sendo alterada nos últimos anos. Com isso, os programas adotaram estratégias para se ajustar ao novo formato de formação, o que envolveu a reorganização da estrutura curricular, conforme destacado no seguinte relato: "Muitos alunos passavam na versão anterior a utilizar grande parte do seu tempo cursando disciplinas e era uma perspectiva de formação em que se privilegiava a formação do professor" (C2).

Para o coordenador C2, um dos efeitos desse tipo de formação foi não dar conta de qualificar os professores para a produção de conhecimentos, o que impactou negativamente no incremento acadêmico da área. Na discussão desse assunto, Tani (2016) propõe que a pós-graduação em Educação Física perspective a formação do "pesquisador que ensina", invertendo a premissa do paradigma anterior, que buscava formar o "professor que pesquisa".

O entrevistado C3 destacou que, em seu entendimento, um processo formativo de qualidade perpassa não somente pela pesquisa e a docência, mas também pela preparação para o exercício de cargos administrativos. Ainda, $\mathrm{C} 3$ enfatizou que deveria ter um equilíbrio entre pesquisa e docência: "O ideal seria trabalhar essas duas perspectivas em condições iguais, de modo dialogado, ou seja, ao mesmo tempo em que eu me qualifico como docente, eu me qualifico como um pesquisador". Com um pensamento análogo, $\mathrm{C} 2$ afirmou: "Eu julgo que ter uma formação que valorize não só a pesquisa é fundamental para os estudantes. Ter uma formação que auxilie a formação do professor para a sala de aula" (C2).

Nota-se a presença de ambiguidade entre os dois núcleos formativos na pós-graduação em Educação Física. As narrativas dão pistas de que a formação para a pesquisa se destaca em relação à formação para a docência e se apresenta mais bem estruturada na dinâmica interna dos cursos. Em diálogo com Elias (2011), compreende-se que as relações estabelecidas nos cursos em análise não são personificadas, mas acabam por se manifestar na configuração e evidenciam as relações de poder que se estabelecem entre os grupos sociais.

Assim, os dados trazem indícios de que a coerção exercida nessa configuração acaba afastando os sujeitos de um senso de realismo do jogo, o que acaba por fortalecer a polarização entre pesquisa e docência e os impede de avançar e incrementar o processo formativo dos cursos em que se vinculam. Por conseguinte, fica a sensação de que essa falta de realismo dificulta que os sujeitos estabeleçam diálogos produtivos, que conjecturem um projeto ampliado de formação para os mestres e doutores.

Ao mesmo tempo que os sujeitos sentem a necessidade de mudanças de paradigma e da ampliação da formação ofertada, ao serem expostos ao sistema de coerção da configuração, acabam empregando os referenciais já instituídos para jogarem o jogo, e para conquistarem e/ou manterem suas posições. Elias (2011) assegura que, as redes de relações configuram estruturas sociais e pessoais, que ao forjarem identidades coletivas, individuais e de pertencimento, produzem sentidos e significados específicos para a vida em grupo.

Em um jogo, existe uma proporção de poder que evidencia que quanto mais houver desequilíbrio entre as forças dos adversários, mais as jogadas de um jogador poderão determinar as jogadas do outro e controlar o andamento e o resultado do jogo (Elias, 2011). O desequilíbrio parece integrar à pós-graduação em Educação Física, já que existem dissonâncias não só entre os agentes, mas também entre as subáreas que a compõe. A própria estrutura curricular é impactada, como foi comentado pelos coordenadores dos cursos.

A respeito desse assunto, os coordenadores ( $C 1$, C2, C3) se posicionaram sobre a recomendação do Documento de Área de 2013, da Área 21 da Capes, que versa, entre outras questões, sobre a estrutura curricular dos cursos e enfatiza que os programas devem proporcionar uma sólida formação didático-pedagógica e científica aos discentes da pós-graduação. O C1 afirmou que o programa não contempla um grupo de disciplinas que discutam as bases epistemológicas e a formação didático-pedagógica, e que encontra dificuldade em conseguir docentes que se disponham a trabalhar com esse tipo de conteúdo.

Nessa mesma linha, C2 pontuou que no momento atual, o programa não apresenta uma grade de disciplinas obrigatórias, defendendo uma estrutura curricular mais flexível, sem a organização de disciplinas de núcleo comum. Percebe-se, por via desses depoimentos, que existe uma carência no âmbito da formação didáticopedagógica docente. Para C3, o currículo flexível tem prejudicado a formação docente: "Perdeu-se esse espaço de uma formação mais ampliada, de acesso a um conhecimento não só específico, porque você não sai do 
programa mestre em Fisiologia, você não sai mestre em Esporte; você sai mestre e sai doutor em Educação Física".

Assim, os dados sugerem um tensionamento em termos das percepções dos sujeitos sobre a formação ofertada. Há uma coerção que se produz nessas relações devido à interpendência existente entre os indivíduos. Essa coerção é exercida sobre as tomadas de posição dos sujeitos e, muitas vezes, eles nem mesmo têm consciência disso. Elias (2011) ajuda a compreender que, quanto mais o jogo se torna complexo, maiores são as dificuldades dos jogadores em organizar suas estratégias de ação.

É importante destacar que, a pós-graduação brasileira se encontra em pleno desenvolvimento e, consequentemente, esse sistema se apresenta cada vez mais complexo, dificultando a forma das pessoas se relacionarem no domínio do mesmo. Quanto mais complexa for a configuração, mais a orientação do jogo se tornará opaca para um jogador individual (Elias, 2011). Assim, a coerção existente na configuração incide na dinâmica dos cursos investigados e nas relações estabelecidas entre os indivíduos, o que torna esse jogo cada vez mais difícil de jogar.

\section{CONCLUSÕES}

O percurso investigativo empreendido nessa pesquisa destacou os aspectos que influenciam o jogo acadêmico no contexto dos programas de pós-graduação em Educação Física. Em síntese, constatou-se que os interesses transitórios deflagrados na configuração perpassam por demandas dos grupos constituídos dos programas investigados. Nesse quadro de relações mútuas, complexas, consentidas e conflituosas, os jogadores mobilizam ações com a intenção de conquistar uma condição privilegiada para participar desse jogo.

Sendo assim, responder positivamente aos padrões instituídos pela CAPES, definir critérios cada vez mais rigorosos dentro da área e competir com a produção intelectual qualificada são condições estrategicamente acionadas, muitas vezes, de forma inconsciente pelos jogadores, para que possam continuar participando do jogo, a partir de uma posição favorável. Essa dinâmica, inevitavelmente acaba repercutindo no processo de formação dos mestres e doutores.

Além disso, é apropriado destacar que a polaridade evidenciada entre pesquisa e docência tem dificultado que diálogos sobre uma possível equalização se firmem. Nesses termos, verifica-se que, embora os avanços que decorrem dessa dinâmica favoreçam o fortalecimento da atividade científica da área, a polarização identificada não favorece uma formação mais relacional para os estudantes. A dinâmica da pós-graduação em Educação Física está marcada pelo dualismo, muito embora o cenário de disputa interna dê pistas para que lado a balança de poder tende a pender.

\section{FINANCIAMENTO}

O presente trabalho foi realizado com apoio da Coordenação de Aperfeiçoamento de Pessoal de Nível Superior -Brasil (CAPES) - Código de Financiamento 001.

\section{CONFLITOS DE INTERESSE}

Os autores declaram não haver conflitos de interesse

\section{AGRADECIMENTOS}

Os autores agradecem à Coordenação de Aperfeiçoamento de Pessoal de Nível Superior (CAPES) pelo suporte financeiro aos bolsistas.

\section{REFERÊNCIAS}

Alcadipani R. Resistir ao produtivismo: uma ode à perturbação acadêmica. Cad EBAPE BR. 2011;9(4):1174-8. http://dx.doi. org/10.1590/S1679-39512011000400015.

Amadio AC. Consolidação da pós-graduação "stricto sensu" da Escola de Educação Física e Esporte da Universidade de São Paulo: trajetória acadêmica após 30 anos de produção. Rev Bras Educ Fís Esp. 2007;21:25-36.

Bardin L. Análise de conteúdo. São Paulo, SP: Edições 70; 2011. Castro TG, Abs D, Sarriera JC. Análise de Conteúdo em Pesquisas de Psicologia. Psicologia (Cons Fed Psicol). 2011;31(4):814-25. http://dx.doi.org/10.1590/S141498932011000400011.

Elias N. A sociedade de corte: investigação sobre a sociologia da realeza e da aristocracia de corte. Rio de Janeiro, RJ: Zahar; 2001.

Elias N. A sociedade dos indivíduos. Rio de Janeiro, RJ: Zahar; 1994.

Elias N. Introdução à sociologia. Lisboa, PT: Edições 70; 2011.

Fernandes EF, Pacheco ASV, Silva FC, Cabral TLO, Azevedo VSC. Panorama do fenômeno da evasão discente na pós-graduação: uma análise a partir do GEOCAPES. In: Universidade Federal de Santa Catarina, editor. XVII Colóquio Internacional de Gestão Universitária; 2017; Mar del Plata. Florianópolis: UFSC; 2017.

Furtado HL, Hostins RCL. Avaliação da pós-graduação no Brasil. Revista de Educação PUC-Campinas. 2014;19(1):15-23. http://dx.doi.org/10.24220/2318-0870v19n1a2611.

Furtado HL, Naman M. Formação do pesquisador em Educação Física: análises epistemológicas. Revista Pensar a Prática. 2014;17(3):751-65. http://dx.doi.org/10.5216/rpp. v17i3.26504.

Gil AC. Como elaborar um projeto de pesquisa. São Paulo, SP: Atlas; 2010.

Kokobun E. Pós-graduação em Educação Física no Brasil: indicadores objetivos dos desafios e das perspectivas. Rev Bras Ciênc Esporte. 2003;24(2):9-26.

Lahire B. Campo. In: Catani AM, Nogueira MA, Hey AP, Medeiros, C. Vocabulário Bourdieu. Belo Horizonte: Autêntica; 2017. p. 64-66.

Lazzarotti A Fo, Silva AM, Mascarenhas F. Transformações contemporâneas do campo acadêmico-científico da Educação Física no Brasil: novos habitus, modus operandi 
e objetos de disputa. Movimento. 2014;20(esp):67-80. http://dx.doi.org/10.22456/1982-8918.48280.

Lazzarotti A Fo, Silva AM, Nascimento JV, Mascarenhas F. Modus operandi da produção científica da EF: uma análise das revistas e suas veiculações. Revista da EF/UEM. 2012;23(1):1-14.

Manoel EJ, Carvalho YM. Pós-graduação na educação física brasileira: a atração (fatal) para a biodinâmica. Revista Educação e Pesquisa. 2011;37(2):389-406. http://dx.doi. org/10.1590/S1517-97022011000200012.

Mendes VR, lora JA. A opinião dos estudantes sobre as exigências da produção na pós-graduação. Rev Bras Ciênc Esporte. 2014;36(1):171-87. http://dx.doi.org/10.1590/ S0101-32892014000100012.

Minayo MCS, Deslandes SF, Gomes R. Pesquisa social: teoria, método e criatividade. Petrópolis, RJ: Vozes; 2011.

Moreira EC, Tojal JBAG. Prioridades dos programas de pósgraduação stricto sensu em Educação Física: a visão dos egressos. Rev Bras Ciênc Esporte. 2013;35(1):161-78. http://dx.doi.org/10.1590/S0101-32892013000100013.

Nunes SI. Docência universitária em educação física: ideações sobre o acadêmico e o pedagógico [tese]. Uberlândia: Universidade Federal de Uberlândia; 2014.

Pires GL, Poffo BN. A avaliação da pós-graduação em educação física e suas implicações para os periódicos da área: "publicar ou perecer" vale também para os editores. Revista de Educação Física/IPA. 2017;1(1):3-21.

Schnetzler RP, Cruz MN, Martins IC. Marcas e tensões no desenvolvimento profissional de professores do ensino superior. In: Associação Nacional de Pós-Graduação e Pesquisa em Educação, editor. 37ạ Reunião Nacional da ANPEd; 2015; Florianópolis. Rio de Janeiro: ANPEd; 2015.

Silva JVP, Gonçalves-Silva LL, Moreira WW. Produtivismo na pós-graduação. Nada é tão ruim, que não possa piorar. É chegada a vez dos orientandos! Movimento. 2014;20(4):1423-45. http://dx.doi.org/10.22456/19828918.46187.

Souza J. Digressões acerca da ciência aplicada do movimento humano (ou sobre como podem prosperar revoluções simbólicas na área de educação física?). Rev Bras Ciênc Mov. 2019;27(4):43-63. http://dx.doi.org/10.31501/rbcm. v27i4.10179.

Souza JPM, Sanchez Gamboa SA. Educação Física como ciência da prática. In: Colégio Brasileiro de Ciências do Esporte, organizador. Resumos de comunicações científicas, XVI Congresso Brasileiro de Ciências do Esporte e III Congresso Internacional de Ciências do Esporte; 2009; Salvador. São Paulo: CBCE; 2009.

Tani G. Pós-graduação em Educação Física: crescimento e correção da rota. In Moreira WW, Nista-Piccolo VL, editores. Educação Física e esporte no século XXI. Campinas: Papirus Editora; 2016. p. 153-71.

Turnes L. Pesquisa e pós-graduação: um estudo de caso sobre os usos das tecnologias por parte de doutorandos do PPGE/UFSC [dissertação]. Santa Catarina: Universidade Federal de Santa Catarina; 2014.

Vogel MJM. Avaliação da pós-graduação brasileira: análise de quesitos utilizados pela CAPES e das críticas da comunidade acadêmica [tese]. São Paulo: Universidade de São Paulo; 2015. 